\title{
The Smart City from a Public Value Perspective
}

\author{
Ellie Cosgrave \\ Department of Science, Technology, \\ Engineering \& Public Policy \\ UCL, UK \\ Email: e.cosgrave@ucl.ac.uk
}

\author{
Theo Tryfonas \\ Faculty of Engineering \\ University of Bristol \\ Bristol, UK \\ Email: theo.tryfonas@bristol.ac.uk
}

\author{
Tom Crick \\ Department of Computing \\ Cardiff Metropolitan University \\ Cardiff, UK \\ Email: tcrick@cardiffmet.ac.uk
}

\begin{abstract}
This paper explores whether it is useful to view the fundamental ideas behind the smart city concept through the lens of the 'Public Value Management' (PVM) paradigm. It investigates how appropriate ICT investment in cities might be articulated and valued through the concept of PVM. In order to achieve this, it explores the core concepts found in the PVM literature, and draws key connections to the smart city literature. This data is supported through semi-structured interviews with smart city experts. The aim is to understand the potential value of smart city concepts beyond simple optimisation of city processes and cost cutting. This paper concludes that there are conceptual connections between the PVM paradigm and the smart city. It argues that the types of projects adopted, and their success, are inseparable from the political paradigm within which they are undertaken. As such, it takes the view that adopting the PVM paradigm could support the successful delivery of smart cities, predominantly through the ability to understand value beyond the optimisation of systems.
\end{abstract}

Index Terms-Smart Cities, Public Value Management, Leadership, Information Marketplaces, Sustainability

\section{INTRODUCTION}

\section{A. Aims}

This paper explores whether it is useful to view the fundamental ideas behind the smart city concept through the lens of the 'Public Value Management' (PVM) paradigm. It investigates how appropriate ICT investment in cities might be articulated and valued through the concept of PVM. In order to achieve this, it explores the core concepts found in the PVM literature, and draws key connections to the smart city literature. The aim is to understand the potential value of smart city concepts beyond simple optimisation of city processes and cost cutting.

This paper aims to draw tangible links between contemporary public management concepts and ICT innovation. It is intended that this will support city leaders in identifying areas of value from ICT investment that cannot be uncovered by more traditional business case analysis.

\section{B. Methodology}

This paper uses the PVM paradigm as an interpretation instrument to delineate useful links between the often quite abstract concepts discussed in the smart city literature, and the realities of local government delivery. This interpretivist research paradigm is supported by an action research and grounded theory approach. A literature review has been undertaken, which is supported by in-depth semi-structured interviews with several leading smart city experts. The purpose of this data collection was to focus on the core themes in the smart city theory, the espoused value, and the implications and challenges for city leadership in the interpretation and delivery of this value.

This paper is part of a wider action research project that investigates the steps that city leaders can take in order to maximise the social, environmental and economic benefits of ICT in their municipalities. This is achieved through working closely with city leadership, as well as economists, technologists and service providers. Increasingly, there is a strong theme of sustainability: the role and impact of the transformational power of ICT for making our world more sustainable.

\section{Context}

We live in a world transformed by technology, a trend started in the industrial revolution that will extend long beyond our lifetimes. However, over the last 10 years or so there has been a significant shift in the nature of this development. Recent advancements in information \& communications technology (ICT) have seen the scale and role of data and information in every aspect of modern life expand almost exponentially. This information is transforming how we live our lives through better informed decision making that is both conscious to us and invisible to us (via automation/sensors e.g. in smart grids). This transformation has driven increased speculation and research into the implications of ICT on the way a city functions and operates [1] - a dialogue that has largely been captured in the smart city debate.

The transformation to 'smart' is manifest not only in the operational efficiency and optimisation heralded by ubiquitous sensors and actuators, but it has also already altered global supply chains, business models, and the way communities and individuals choose to live their lives [2]. Cities compete with each other to attract private finance and investment within a national and global 'system of cities'. For example, the UK Government's Foresight project The Future of Cities 1 (launched in 2013), will take a long-term look at how UK cities can best contribute to economic growth over the coming decade, taking into consideration wellbeing, equity and social inclusion, all vitally important for cities and their citizens. New ICT (such as smart phones, broadband, 3G), has driven a fundamental change in the way we work (networking through

\footnotetext{
${ }^{1}$ http://www.bis.gov.uk/foresight/our-work/projects/current-projects/futureof-cities
} 
social media, distance working), how we shop (online, price comparison), interact with family and friends (Skype, social media), and our expectations of government (311, open data). ICT has also been at the forefront of a new era of activism and community unity. "In the Arab Spring, social media facilitated action in the Middle East and North Africa (MENA) region, providing a free and accessible method of organising and coordinating demonstrations" [3]. This was echoed in the 2011 London riots, and the subsequent clean-up operation.

Private sector technology companies like Facebook, Amazon and Google have capitalised on this opportunity by using information to provide value to their customers. These companies utilise information as a core asset, and leverage it to create products and services that respond to user desires and expectations. As highlighted in the report "Information Marketplaces: The New Economics of Cities" the current 'information marketplace' in cities already creates value for citizens and contributes to its sustainability [4]. Innovative information-based products and services create jobs and support citizens in navigating and using the city in effective, resource efficient and enjoyable ways, as well as enabling sustainable development [5], [6]. In fact, the 'Smart 2020' report, written as part of The Climate Group's 'Clean Revolution' campaign, found that ICT-enabled interventions could deliver "7.8 $\mathrm{GtCO}_{2} \mathrm{e}$ of emissions savings in 2020. This represents $15 \%$ of emissions in 2020 based on BAU estimation" [7].

However, city leaders are struggling to identify the true sources of value that novel ICT can generate for their municipalities. They are finding it difficult to transform the higher-level concepts evident in the smart city literature into actionable and effective policies, projects and programs that deliver measureable value to the citizenry [8]. This is in part due to the nature of the city itself, which is "an enormously complex and open-ended system, with many intertwining force fields influencing its form simultaneously" [9].

There is also a fundamental misunderstanding of the nature of the change that is occurring. ICT can be used to increase the operational efficiency of a city through applications such as traffic management systems or the implementation of smart grid. However, more than that, ICT is essential in creating a novel and dynamic marketplace that can provide real long term value to the citizenry, both through the services it provides and the continued economic development that it facilitates. City leaders can use this concept to better understand how to engage with ICT, and the smart city to enable them to deliver real value to the modern public. This is a priority theme for the Future Cities Catapult ${ }^{2}$, a global centre of excellence on urban innovation, launched by the UK's Technology Strategy Board in 2013.

Identifying the specific role of new ICT in such a complex system requires a really fundamental understanding of the specific city context, as well as a firm grasp of the vast array of roles for ICT in delivering value to the city. Unfortunately, these two core requirements are rarely found in the same place, and necessitate effective cross-sector engagement, dialogue and action. Volker Buscher, Director of Smart Cities at Arup explains:

\footnotetext{
${ }^{2}$ https://futurecities.catapult.org.uk
}

Effective, appropriate and insightful dialogue is required between city leaders, smart city experts, and the wider community if the complex problems faced by cities today are to be resolved. No single party holds the full set of tools to make informed, appropriate and innovative decisions that can address our contemporary local and global issues...I see a great opportunity for cities to use smart city ideas to transform themselves into thriving, healthy and happy places that are globally competitive. But it will require sensitive and informed dialogue that can be translated into action. [10]

\section{Public Value Management Paradigm}

The concept of Public Value Management (PVM) has grown out of and developed upon the New Public Management (NPM) paradigm. "Much of the NPM literature is clear about the deficiencies yet NPM has remained the dominant policy model in the public sector for over 20 years" [11]. NPM broadly asserts that market forces can be leveraged to deliver more cost effective and efficient services to citizens, and focuses on the utilisation of metrics and monitoring to evaluate success.

Hefetz and Warner argue however, "the social values inherent in public services may not be adequately addressed by the economic efficiency calculus of markets" [12]. In response to this, PVM takes a more pragmatic approach to the delivery of public services and "presents the achievement of public value as its core objective" [13]. It seeks to take into account a wider variety of factors when deciding when and how to deliver services, incorporating concepts beyond simple cost cutting. "Public Value has been described as a multidimensional construct - a reflection of collectively expressed, politically mediated preferences consumed by the citizenrycreated not just through 'outcomes' but also through processes which may generate trust or fairness" [14].

Horner and Hazel define Public Value as the correlate of private value or shareholder return: "The value may be calculated through economic prosperity, social cohesion or cultural development. Ultimately, the value - such as better services, enhanced trust or social capital, or social problems diminished or avoided - is determined by the citizen" [15]. This is a distinct step away from the Net Present Value (NPV) approach, which attempts to gauge success through the analysis of measures and metrics.

"Public Value Management does offer a new paradigm and a different narrative of reform. Its strength lies in its redefinitions of how to meet challenges of efficiency, accountability, and equity and in its ability to point to a motivational force that does not rely on rules or incentives to drive public service reform" [13].

"The 'Public Value' approach has fast become an established (if as yet minority) approach to assessing the success (or otherwise) of public services and organisations in the UK, Australia and some other countries" [16]. It represents an approach that appears to be feasible and realisable, and is therefore appropriate for a more detailed investigation. 


\section{A. Core Themes}

The PVM paradigm relies on the public sector gaining a legitimate mandate for action, which is considered to be the only justification for government action. Gaining this legitimacy requires a combination of:

- Performing efficiently;

- Being accountable;

- Being responsive to public needs;

- And gaining trust.

Of course, these parameters are interrelated, but a focus on each of these is required by the PVM paradigm if public sector actors are to gain and maintain a mandate for action.

This legitimacy provides an opportunity for public managers to stretch their traditional politically-driven mandate for action, and align actions more closely with genuine public needs. "The Public Value approach suggests that actually public managers need not be so passive - that they can supplement and enhance the link between citizen and delivery within the context of continued accountability to the political principle and awareness of the wider authorising environment" [17].

\section{B. Performing Efficiently}

Although cost cutting is not the primary focus of PVM, the efficient and appropriate use of resources is an imperative for ensuring legitimacy in public sector actions. This means that city leaders must seek to increase the efficiency of their operations and services, as well as ensuring that new projects invested in represent the best value in the longer term. This includes the requirement to consider the through-life implications of projects and programs including the end-of-life transferability and adaptability of the scheme as highlighted in cradle-to-cradle thinking [18].

Furthermore, the PVM paradigm challenges leaders to think more deeply about the services they choose to provide to their citizens. As Stoker argues, simply "providing services is no longer a sufficient justification for state intervention funded by citizens, whether those services are provided directly or commissioned" [13]. Instead, city leaders must evaluate their role in delivering the value that those services traditionally represented. For example, the city might have a responsibility to ensure that their citizens are educated. In the past, this has been interpreted as a mandate to run schools, and other education services. The PVM paradigm calls for cities to consider how best to deliver education in a city, rather than how best to run education services. It focuses on value creation rather than service delivery. This frees up city leaders to be more creative and responsive to local needs.

Importantly this does not dictate a particular political path or tendency. Baptista argues that the opportunities created by the smart city "may lead us to a more fundamental choice between a privatised government (in which most issues are dealt with according to commercial relationships and principles, with services paid for by clients) and traditional, public government (in which many services considered to be of public interest are provided to citizens and businesses according to a variety of criteria not necessarily linked to commercial considerations)" [19]. However, "city leaders must take care to ensure that the ability of ICT to outsource city services does not dictate the political direction, but that instead, investment in ICT is derived from a sound articulation of political, social and cultural values" [20].

The PVM paradigm calls for leadership to consider the role that they should play in delivering public value in order to achieve policy goals. While the PVM approach may lead to the adoption of a similar project or program (i.e. a serviceoriented approach to delivery), the conceptual leap is important as it releases opportunities for the creation of value beyond the traditional service approach. In this way, "the public value paradigm demands a commitment to goals that are more stretching for public managers than those envisaged under previous management regimes" [13]. Furthermore, Kearns argues that "[Public Value] can be used both as an aid to judgment by governments when deciding what activities to undertake as a yardstick against which to access government performance" [21]. In this way, the PVM paradigm is reflexive, and can be used to both define and gauge the success of government investment.

\section{Being Accountable}

In order to achieve legitimacy, the public sector must show itself to be transparent and accountable. "Public value argues that public services are distinctive because they are characterised by claims of rights by citizens to services that have been authorised and funded through some democratic process" [22]. This democratically appointed authority means that public sector decision makers are accountable to the public.

The political move towards accountability and openness has accelerated in recent years. "In his first day in office, President Barack Obama issued the open government directive committing his government to the three principles of transparency, participation and collaboration as the cornerstone of an open data government" [11]. January 2010 saw the official launch of data.gov.uk ${ }^{3}$ ("Opening up Government"), releasing public data to help people understand how government works and how policies are made. Similarly, the 2010 UK Conservative Party manifesto claimed that the party intended to "make government more transparent" [23].

This move to transparency and accountability as the foundation for public sector action has been partly in response to a general push for a more open approach to governance, particularly around the topic of open data. This has been compounded by increasing media scrutiny of government in recent years, particularly through social media. In this way, "The same technological advances which have opened informatory access and accountability of public services also can cause intense pressure on public managers for managing demand and expectations" [17]. Moreover, "because of rising expectations, technological advances and 24-hour media scrutiny the exchanges between politicians, managers and the public are of greater intensity and any confusion in roles become politically salient and can feed into a loss of public confidence about the stewardship of both manager and politician" [17]. To combat this, the public sector has had to respond creatively to

\footnotetext{
${ }^{3}$ http://data.gov.uk/
} 
how it engages with and incorporates public values into their decision-making processes.

\section{Being Responsive to Public Needs}

The PVM paradigm acknowledges that public leaders are operating in a complex and evolving environment. In this light it argues that leaders must adopt a dynamic approach to stakeholder engagement and longer-term decision making, being responsive in the light of complexity. This is not to say that governments should not plan ahead and lay down concrete strategies, but that the strategies that they do employ must take into account that the context that the strategy is enacted in will change over time. An understanding of this must be incorporated into the strategy in order to make it more robust in the longer term. "The adoption of a public value approach to public services needs to take account of both empirical complexities in the delivery landscape and in how the rules of engagement between politicians and managers are interpreted and enacted" [17].

Here, the relationship internally within local authorities is key, but there is also a clear need for genuine dialogue with citizens. This dialogue must be carried out in a way that reflects the diversity of citizen needs, values and aspirations in an appropriate way. It must also ensure that dialogue is set up in a way that enables it to be incorporated into government planning and policy. This means that it must be timely, specific and seek genuine insight.

\section{E. Gaining Trust}

All claims to legitimate action are founded on an underlying trust between core actors. This is achieved through processes such as being responsive, accountable, and efficient, but also requires effective communication. A report from the Work Foundation on measuring Public Value, puts trust and legitimacy at the center of their model. It claims "trust and legitimacy is placed at the top of this list deliberately, in line with the Public Value approach, because without it none of the other (aspects of public value) are possible" [16]. Likewise, in this paper, we argue that the development of trust in government and governance decisions is an imperative for successful public sector leadership.

\section{The Core PRinciples of SMART Cities}

The concept of the smart city has gained traction in recent years and although it has been coined for a variety of purposes, it broadly refers to a city that is using new ICTs innovatively and strategically to achieve their aims. This should not necessarily be interpreted as top-down vision delivered solely through government investment. Quite the opposite, the smart city is largely an organic 'system of systems' [24] which comprises an ecosystem of products, services, companies, people and society that are working together creatively to foster innovation within the city. "Smart cities cannot be defined by one application, or central organising body, that sets preprogrammed limits. They will be defined by individual citizens, who are anxious to collaborate with each other...to create devices and applications that solve specific problems. Smart cities will be places that foster creativity, where citizens are generators of ideas, services and solutions, rather than passive recipients of them" [25].

A clear example of the evolution of this information marketplace is the website Openly Local ${ }^{4}$, which scrapes data from various local government sources, and brings it together in one accessible place, in order to create an "open and unified way of accessing Local Government information". This information can then be used for a variety of purposes, including the development of innovative products and services for citizens.

While city leaders and local authorities are key stakeholders in this system, they can by no means directly conduct and control this marketplace. However, they have a responsibility to determine what their role might be in fostering a healthy marketplace that can support the delivery of their objectives. This involves investigating how they should invest, at what time and for what purpose.

In that light, it is helpful for governments to adopt an understanding of smart cities that lies beyond the optimisation of city services. Working with the Smart Cities team at Arup over the past two years, this research has explored the concept of the smart city through a variety of meetings, workshops and practical applications. Through this engagement, three core interrelated categories of smart city value have emerged [4], [26]. These are broadly:

- Optimisation;

- Service Innovation;

- Information Marketplace.

Each category represents a different tier of conceptual integration of themes and ideas. While 'optimisation' looks quite specifically at the operational efficiency of a given system, the development of an 'information marketplace' integrates many system externalities, and deals with a wider variety of themes.

\section{A. Optimisation}

Many people and organisations have pushed the idea that the smart city, revolved around ubiquitous sensing and actuation, can deliver optimisation of city services. For example, a Forrester report describes the smart city as "A city that uses information and communications technologies to make the critical infrastructure components and services of a citymore aware, interactive, and efficient" [27]. There is a significant focus on the use of ICT improve the operational efficiency, or in reducing provisioning costs of core city services. This is exemplified by smart grid projects. Here, information is collected in real time about the energy usage at different areas of the grid. This information is then used to optimise the flows in the system. Some smart grids have actuation functionality that enables them to balance the load on the grid - thereby reducing peak requirements.

The word 'optimisation' has been tangled up in significant debate when referring to engineered systems; the move towards a 'fully optimised' approach to systems has led to the increased vulnerability of systems by the tendency to engineer-out redundancy. This can lead to single point of failure systems that

\footnotetext{
${ }^{4}$ http://openlylocal.com/
} 
are not resilient to change, and cannot cope with unexpected events.

In this paper, we to refer to optimisation in the sense of making improvements to a system in such a way that is most suited to the delivery of its purpose. This does require a focus on resource efficiency, but also incorporates process improvement, and building up resilience to unexpected events through access to more granular information about the realtime state of the system. In this way, optimisation should be understood in terms of improving the quality of the services provided, at lower resource cost, and with increased resilience to failure.

City service optimisation is an internally focused area for cities, where they investigate ways in which their internal processes and functioning can be achieved more effectively. Chris Namih, Consultant (Smart Cities) at Arup, explains that:

Optimisation is internal within the provision of services as they stand. [28]

\section{B. Service Innovation}

The concept of service innovation in smart cities includes the development of novel ways of delivering service outcomes in the city. This goes beyond optimisation, offering a paradigm shift in the way that services are delivered, rather than improving (or 'optimising') within a given way of doing things. It offers new and more innovative ways of delivering services within the city.

A service innovation will have an implication for the way in which a user behaves, or experiences the city. An example of this might be the move to a smart ticketing system for public transport within the city. Transport for London's Oyster card system ${ }^{5}$ resulted in a transformation in the way people interacted with public transport in several ways. Chiefly, flexible charging allowed people to roam more freely around the city, particularly in going beyond the zone for which they had bought a travel card. It also increased efficiency of bus systems by significantly speeding up the boarding time required.

The Oyster card data has also provided significant insight into user behaviour [29], which has been useful for research, and system optimisation. The opportunities for this detailed dataset have not yet been fully realised, but it is recognised that, if used innovatively, it can be used to both optimise the system and contribute to the information marketplace as described below.

\section{Information Marketplace}

The concept of the information marketplace argues that there is a wider economy developing around the smart city that is outside the boundaries of the local council. This marketplace relies on information as a core asset to drive economic development and other social and environmental aims. So, in the case of transport, innovative companies or individuals could use anonymised oyster card data to create novel products and services. The Information marketplaces report argues, "By unlocking technology, infrastructure and public data, cities can

\footnotetext{
${ }^{5}$ http://www.tfl.gov.uk/tickets/14836.aspx
}

open up new value chains that spawn innovative applications and information products that make possible sustainable modes of city living and working" [4]. This concept is at the centre of fostering the information marketplace. Chris Namih explains:

For me an information marketplace... creates an ecosystem where third parties can deliver services or certain aspects of them, or entirely new services by being enabled by information. [28]

Thus, fostering this ecosystem of benefits supports a city in becoming more competitive, as well as achieving their core high level objectives.

These buckets arent just technology-focused. You can optimise through process change or business organisation change, and you can do the same in service innovation. Technology is often involved, and technology can lead to these changes, but it is not the only factor. [28]

This means that the smart city concept is concerned with more than just the implementation of technology. It is also concerned with the ecosystem that can be built up around that technology in order to create positive social, economic, environmental and political outcomes. This requires both topdown engagement through hard infrastructure investment and visioning, as well as a bottom-up energy to capitalise upon and drive innovation in ICT and service provision.

The multiple layers of the smart city story means that, while governments do have a significant role to play in the creation of smart cities (particularly through the optimisation of city services) there are a vast number of stakeholders that lie outside the bounds of local government. This is particularly relevant to the creation of information marketplaces within the city. As such, city leaders need to understand how to engage with this evolving information community, and understand their needs in relation to economic and social drivers, as well as investing in the existing marketplace within their city.

\section{THE PUBLIC VALUE LENS: THE RELATIONSHIP TO SMART CITIES}

Achieving city objectives through smart city projects requires political and civil engagement. Léan Doody, Smart Cities Associate at Arup, explains that effective action requires:

\section{A certain leadership in the council to look at the role of IT information in achieving top level goals. [30]}

This does not exclude the importance of the bottom-up creation of smart cities, but demonstrates that the types of projects that a city engages/invests in, and their effectiveness, are inextricably linked to the prevailing political and cultural paradigm.

Two-thirds of UK government ICT projects fail [31], partly due to the fact that "city administrators often fail to acknowledge projects as being complex or strategic and neglect many 'softer' issues that are essential for a project to succeed" [4]. This high failure rate has also been due to ICT providers under bidding in a competitive tendering process in order to win work, leading to under-resourced and under-supported projects. Measures have been put in place, for example the creation of 
the Major Projects Authority ${ }^{6}$, to improve project performance for the taxpayer, as well as the creation of the Government Digital Service ${ }^{7}$ in 2010 to implement the UK Government Digital Strategy [32]. However, projects have failed as a result of being largely driven by the creation of 'political capital' for the presiding politician, which may not have a rigorous founding in the realities of successful project delivery.

ICT projects in cities cannot be seen as distinct from their political, social, or economic context, and therefore must be analyzed as part of that system. This section seeks to identify how the political paradigm adopted in a city relates to the success of a smart cities program, with a particular focus on PVM.

Figure 1 maps the core themes discussed in the PVM literature to the three 'buckets' derived in the smart cities section. Conceptualising the problem in this way highlights a two-way relationship between PVM and smart cities. In one sense, new ICTs are pushing the need for governments to adopt a PVM approach because of increased media scrutiny and increased skepticism from the public. In another sense, adopting a PVM approach could help city leaders to understand the potential value of smart cities more comprehensively and holistically.

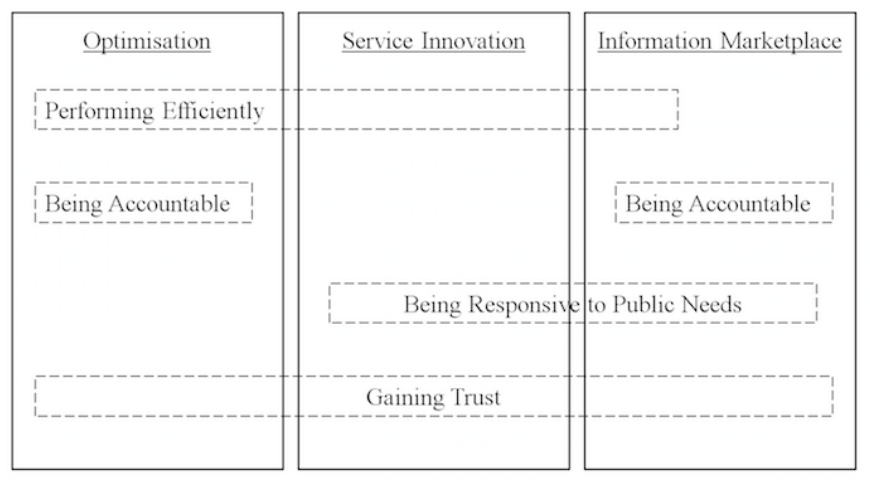

Figure 1. Relationship between the smart city and the public value management paradigm

\section{A. Performing Efficiently}

As previously discussed, the PVM paradigm espouses that efficient and appropriate use of resources is a central tenet in public sector legitimacy. There are multiple examples that highlight smart cities contributing to resource efficiency in city service delivery (e.g. the Águas de Cascais roll-out of 'TaKaDu' which is a "web-based service that allows the water utility to detect leakage and network problems as they occur" [33]).

The obvious link here is in the 'optimisation' category of smart city projects. These optimise city systems in order to reduce resource consumption and deliver better services. However, because the PVM paradigm calls governments to reassess how they provide value in the city, a distinct crossover with the information marketplace emerges. In the creation of the information marketplace, city leaders need to understand

\footnotetext{
${ }^{6}$ https://www.gov.uk/government/groups/major-projects-authority

${ }^{7}$ https://gds.blog.gov.uk/about/
}

how to foster public value in the wider city ecosystem. This might be through investment in the technology sector, fostering innovation through funded competitions (e.g. the Apps for Democracy ${ }^{8}$ competition in Washington, which "yielded 47 web, iPhone and Facebook apps in 30 days a $\$ 2,300,000$ value to the city at a cost of $\$ 50,000 "$, which was given to the developer of the winning app as a prize) or running appropriate events and symposiums. This represents a clear progression from the direct approach of delivering value exclusively through public sector service provision, to an understanding that value can also be derived through fostering positive externalities.

\section{As Chris Namih explains:}

\section{In understanding the information marketplace, quite} often it is the mind-set that needs to be re-jigged. [28]

The PVM approach supports this shift in focus by arguing for a more holistic approach to value creation in the city that does not focus solely on the delivery of services. In this way, an adoption of the PVM approach may support leaders in capitalising on the information marketplace.

\section{B. Being Accountable}

The PVM paradigm argues that in order to gain legitimacy, public leaders must be accountable to the public. In reality however, while governments and political leaders are often held accountable for certain services, they have in some cases, given over the responsibility for delivery over to third parties. This has restricted their ability to impact upon, or change the way in which those services are delivered. If governments are to have more control over the public services that they are accountable for, they must think creatively about how to engage with responsible parties. ICT may have a role to play here in fostering better communications, or joining-up infrastructure projects so that there is greater interrelationship.

The concept of accountability also assumes that there is an object or body to whom a party is accountable. In the case of cities, this body is the citizenry. If genuine accountability is to be demonstrated then city leaders need to foster effective communication with citizens, in a way that enables citizens to challenge and appreciate the ways in which city leaders are accountable for their actions. As such, accountability for public spending may require a more open approach to governance. This may be in the form of opening up city dataset to the public, which would in turn contribute to the information marketplace. This demonstration of accountability is also heavily linked to the fostering of trust as discussed in Section IV-D.

\section{Being Responsive to Public Needs}

A key part of the PVM paradigm is a responsive and reflexive approach to the needs of the citizenry. Effective public dialogue that can be fed into investment decisions is essential in achieving this. Léan Doody, explains that one of the key principles of smart cities is:

About making sure the flow of information is not just one way, so its about getting informed commentary

\footnotetext{
${ }^{8}$ http://www.appsfordemocracy.org/
} 
and ideas back from the public...Technology platforms potentially have a huge role in enabling people to communicate directly. This opens up government at different levels, so it's a kind of flattening of the organisation and they way that people are able to communicate directly with maybe more junior people who actually have a voice now through Twitter or seem to be a bit more happy to engage. [30]

Importantly, this interaction and understanding of citizen needs must be translated into appropriate action and investment. In Los Angeles, transport planners are using web platforms strategically in order to engage with the public to inform their planning process. Part of this includes a 'virtual town hall' where subjects are opened up for discussion over several days; this is accompanied by face-to-face workshops. The diversity of consultation approaches means that the city is able to capture a wider variety of citizens needs than would have been previously possible. Importantly, the planners have a structured plan to feed back findings to inform planning decisions at the appropriate time in the process [34].

\section{Gaining Trust}

New ICT is also driving city leaders to a more open and transparent approach. Increased media coverage has become so ubiquitous through the rise of Web 2.0 and social media that governments are under unprecedented levels of scrutiny. This has driven the political transparency agenda, firstly in the US, and now increasingly in Europe and elsewhere. Furthermore, now that the technology is at a level where it really can be used to aggregate huge levels of personal data about citizens and their behaviour, cities that do not take an open approach may be accused of operating 'big brother' type states. Léan Doody explains that ubiquitous ICT and smart technologies:

Would also allow a horrible dystopian view of the future- look at how technology is being used in more repressive regimes. [30]

Citizens and organisations will start to question leaders that chose to cut themselves and their operations off from public dialogue, especially now that there are widespread technology platforms that make engagement so much easier. The PVM paradigm's emphasis on being accountable to citizens and gaining trust, is clearly going to play an important part in managing the relationship between citizens and public and political leaders, whether or not they have a desire to engage with the transparency and open data movement.

Citizens can become quite sensitised to perceived privacy violations with respect to their personal data. This has been exemplified by Google's change in privacy policy which enabled them to "cross-pollinate personal user data recorded on any of its 60 products" [35]. This incited a severe reaction from the international community: "Lawmakers, privacy authorities, technical experts, and privacy organizations around the world (released) public statements and direct letters to Google representatives that (were) critical of the new policy. Advocacy groups criticise(d) and condemn(ed) the changes, and the European Union, Japanese, and Canadian privacy authorities have released statements indicating that the new policy may violate their domestic privacy laws" [36].
There are important lessons for any organisation that is in control of significant amounts of public data, especially in public organisations that are directly accountable to the public. Holders and users of public data open up channels for the development of mistrust between themselves and the public, which can severely damage long term relationships, and consequently the effectiveness of public service provision.

In order to combat this, city leaders must demonstrate trustworthiness by becoming custodians of public data, utilising it only when they can demonstrate a tangible link to the delivery of public value. This is a complex task that requires further investigation.

\section{CONCLUSION}

This paper has highlighted that there are conceptual connections between the PVM paradigm and the concept of the smart city. It argues that the types of projects adopted, and their success, are inseparable from the political paradigm within which they are undertaken. As such, it takes the view that adopting the PVM paradigm could support the successful delivery of smart cities, predominantly through the ability to understand value beyond optimization of systems.

The PVM paradigm encourages governments to conceptualise their actions from a new perspective, requiring them to place the creation of public value at the center of their focus, rather than the provision of efficient services. This subtle shift in focus actually requires a profound leap in the way in which decisions are made, and that value from projects can be analysed. The PVM approach offers a key for city leaders to understand the value of smart city projects, and importantly provides a political legitimacy for investment in it. This is especially important when city leaders are trying to justify investment in the information marketplace. Here, certain values need to be incorporated that are not measureable in the traditional sense - that do not sit neatly alongside traditional metrics, but that require investment nonetheless.

If government is able to understand itself as a body that is dealing with complexity, trying to be responsive to needs and think in the long term, and not necessarily metric oriented, it can get more out of smart cities. This is because it is able to articulate value that lies beyond optimization and bottom line efficiencies. So, if city leaders are able to look at ICT through a public value lens, it helps them to understand the value of ICT projects and smart cities. From this viewpoint city leaders can come to make better decisions, based on a more coherent understanding of the role of technology in achieving their core aims.

This paper identifies a two-way relationship between PVM and smart city delivery. Firstly, new ICT (or smart city concepts) pushes the need for governments to adopt the PVM paradigm through:

- Requirement for transparency;

- Increased scrutiny from social media.

Equally, smart city concepts also support the delivery of public value through:

- Data provision (and open data); 
- Effective communication;

- $\quad$ Supporting dynamic governance and ability to respond to citizen needs;

- $\quad$ Dealing with complexity;

- Fostering creativity.

The new perspective offered by PVM enables local government to understand the value of smart city beyond efficiency gains that can be achieved through optimisation. This paper argues that applying the traditional NPM approach to smart cities restricts a citys ability to invest in ways that deliver the greatest value to the citizenry. This is especially relevant for value that cannot always be measured through standardized metrics and measures, or through bottom-line cost cutting. For adequate smart city investment, city leaders must be able to grapple with the real-life complexity of their challenge. They must understand that the problems they face are multifaceted, interrelated and dynamic. This necessitates the genuine public engagement, effective internal communication and collaboration, and responsiveness as represented in the PVM approach.

This paper argues that taking a public value management approach can support cities in understanding the value of ICT investment, as well as increasing the likelihood of success of smart city interventions. However, it does not claim that adopting the PVM paradigm is a requirement for smart city delivery, or that is holds exclusivity over smart city implementation. There may well be other management paradigms that support the delivery of smart city concepts. As Léan Doody explains:

\section{I think the point about technology is that it is about your intentions more than the technology, the technology will allow lots of different outcomes. [30]}

Equally, we do not intended to claim that the adoption of PVM will necessarily deliver valuable smart city interventions. This paper merely means to highlight the potential value in viewing the delivery of smart cities through a public value lens.

\section{FUTURE WORK}

This paper is part of a wider action research project that investigates the steps that city leaders can take in order to maximise the social, environmental and economic benefits of ICT in their municipalities. From a sustainable development perspective, we note the imperative to connect within cities (which, by inference, includes technology) and the increasing importance of connecting among cities: a global community of connected cities committed to sustainability. We intend to use the concepts developed in this paper, and other work to continue to deepen our understanding of the challenges faced by city leaders in approaching smart city delivery.

Firstly, we intend to use this conceptual foundation to work with a city to understand the implications of smart cities for their investment and organisational decisions. We will take an action research approach to develop a systems-based process/framework that allows cities to find the cross sector implications of the smart city, and guide decision-making. Through interviews, case studies and workshops, we will seek to identify the implications of the findings for city leadership in terms of management processes and organisational structure. Given the new understanding of the role of technology, how might they now evaluate technology investment projects in the future? Does it have an implication for the metrics they are able to employ? What limitations and drawbacks might they still face?

\section{ACKNOWLEDGMENT}

Part of this work has been supported by Arup and the University of Bristol's Industrial Doctorate Centre in Systems (EPSRC Grant EP/G037353/1). The first two authors would also like to thank Volker Buscher and Professor John Davis for their support in preparing earlier versions of this paper.

\section{REFERENCES}

[1] N. Odendaal, "Information and communication technology and local governance: understanding the difference between cities in developed and emerging economies," Computers, Environment and Urban Systems, vol. 27, no. 6, pp. 585-607, 2003.

[2] N. Komninos, Intelligent Cities: Innovation, Knowledge Systems and Digital Spaces. Routledge, 2002.

[3] P. Bright, "How the london riots showed us two sides of social networking," August 2011, http://arstechnica.com/techpolicy/news/2011/08/the-two-sides-of-social-networking-on-displayin-the-london-riots.ars (accessed 2014-02-12).

[4] Arup, The Climate Group, Accenture and Horizon, University of Nottingham, "Information Marketplaces: The New Economics of Cities,", November 2011

[5] W. Wagener, "Connected and Sustainable ICT Infrastructure," Connected Urban Development, 2008.

[6] N. Villa and S. Mitchell, "Connecting Cities: Achieving Sustainability Through Innovation," Cisco, October 2010.

[7] The Climate Group, "SMART 2020: Enabling the low carbon economy in the information age," 2008, Global eSustainability Initiative (GeSI).

[8] R. G. Hollands, "Will the real smart city please stand up? intelligent, progressive or entrepreneurial?" City, vol. 12, no. 3, pp. 303-320, 2008.

[9] A. Sevtsuk and J. Beinart, "The effects of ICT on City Form," MIT School of Architecture and Planning, 2005.

[10] V. Buscher, April 2012, Interview.

[11] E. Coleman, "From New Public Management to Open Governance: A New Future or The More Things Change the More They Stay The Same?" Master's thesis, University of Warwick, UK, 2011.

[12] A. Hefetz and M. Warner, "Privatization and Its Reverse: Explaining the Dynamics of the Government Contracting Process," Journal of Public Administration Research and Theory, vol. 14, no. 2, pp. 171-190, 2004.

[13] G. Stoker, "Public Value Management: A New Narrative for Networked Governance?" The American Review of Public Administration, vol. 36, no. 1, pp. 41-57, 2006.

[14] J. O’Flynn, "From New Public Management to Public Value: Paradigmatic Change and Managerial Implications," Australian Journal of Public Administration, vol. 66, no. 3, pp. 353-366, 2007.

[15] L. Horner and L. Hazel, "Adding Public Value," The Work Foundation, January 2005.

[16] C. Talbot, "Measuring Public Value - A competing values approach," The Work Foundation, October 2008

[17] F. Gains and G. Stoker, "Delivering 'Public Value': Implications for Accountability and Legitimacy," Parliamentary Affairs, vol. 62, no. 3, pp. 438-455, 2009.

[18] W. McDonough and M. Braungart, Cradle to Cradle: Remaking the Way We Make Things. North Point Press, 2002.

[19] M. Baptista, "eGovernment and State Reform: Policy Dilemmas for Europe," Electronic Journal of e-Government, vol. 3, no. 4, pp. 167174, 2005. 
[20] E. Cosgrave and T. Tryfonas, "Exploring the Relationship Between Smart City Policy and Implementation," in Proceedings of the 1st International Conference on Smart Systems, Devices and Technologies (SMART 2012), 2012, pp. 79-82.

[21] I. Kearns, "Public Value and E-Government," Institute for Public Policy Research, 2004.

[22] D. Coats and E. Passmore, "Public Value: The Next Steps in Public Service Reform," The Work Foundation, October 2008.

[23] The Conservative Party Manifesto, "Why we think you should vote for us,", 2010.

[24] C. Harrison and I. Abbott Donnelly, "A Theory of Smart Cities," in Proceedings of the 55th Annual Meeting of the International Society for the Systems Sciences (ISSS), 2011, pp. 7-22.

[25] U. Haque, "Surely there's a smarter approach to smart cities?" April 2012, http://www.wired.co.uk/news/archive/2012-04/17/potentialof-smarter-cities-beyond-ibm-and-cisco (accessed 2014-02-12).

[26] E. Cosgrave, K. Arbuthnot, and T. Tryfonas, "Living Labs, Innovation Districts and Information Marketplaces: A Systems Approach for Smart Cities," in Proceedings of the 2013 Conference on Systems Engineering Research, 2013, pp. 668-677.

[27] J. Bélissent, "Getting Clever About Smart Cities: New Opportunities Require New Business Models," Forrester, 2010.
[28] C. Namih, April 2012, Interview.

[29] J. Reades, "Early Views of Public Transit Usage in London," April 2011, http://simulacra.blogs.casa.ucl.ac.uk/2011/04/early-viewsof-public-transit-usage-in-london/ (accessed 2014-02-12).

[30] L. Doody, April 2012, Interview.

[31] Parliamentary Office of Science and Technology, "Government IT projects,", Report 200, July 2003.

[32] UK Government, "Government Digital Strategy", December 2013, https://www.gov.uk/government/publications/government-digitalstrategy (accessed 2014-02-12).

[33] PRWeb, “Águas de Cascais Rolls Out TaKaDu for Water Network Monitoring and Water Loss Reduction," March 2012, http://www.prweb. com/releases/2012/3/prweb9288938.htm (accessed 2014-02-12).

[34] Los Angeles Departments of City Planning and Transportation, "LA2B,' 2011, http://la2b.org/about/ (accessed 2014-02-12).

[35] M. Pinter-Krainer, "Google Enforces New Privacy Policy, Despite International Outcry About Its Implications," March 2012, http://www.consumerwatchdog.org/story/google-enforces-new-privacypolicy-despite-international-outcry-about-its-implications (accessed 2014-02-12)

[36] M. Sutton, "International Reactions to Googles New Privacy Policy," March 2012, https://www.eff.org/deeplinks/2012/03/internationalreactions-googles-new-privacy-policy (accessed 2014-02-12). 